\title{
Successful treatment of IgG4-related hypertrophic pachymeningitis with induction rituximab and dexamethasone followed by maintenance rituximab
}

Karan Seegobin ${ }^{1}$, Muhamad Alhaj Moustafa ${ }^{2,3}$, Nicole Gannon ${ }^{3}$, Katelyn Keller ${ }^{1}$, Jacquelyn Hastings ${ }^{1}$, Vivek Gupta ${ }^{1}$, Han W. Tun ${ }^{1}$, and Liuyan Jiang ${ }^{1}$

${ }^{1}$ Mayo Clinic Hospital Jacksonville

${ }^{2}$ Mayo Clinic

${ }^{3}$ Mayo Clinic's Campus in Florida

September 7, 2020

\begin{abstract}
IgG4-related disease (IgG4RD) with intracranial involvement is rare. We report a 56-year-old male who had an excellent response to rituximab and dexamethasone after going undiagnosed for 5 years. After 3 years of rituximab maintenance, he has no evidence of disease on brain MRI.

\section{Hosted file}

IgG4 Pachymeningitis edited Journal.DOCX available at https://authorea.com/users/339666/ articles/479605-successful-treatment-of-igg4-related-hypertrophic-pachymeningitis-withinduction-rituximab-and-dexamethasone-followed-by-maintenance-rituximab
\end{abstract}


Figure 1. Contrast-enhanced T1 weighted MRI. Before treatment (images A and B) shows diffuse plaque-like thickened enhancing dura (A, arrowheads) and obliteration of the superior sagittal sinus (B, arrow). After treatment (images $C$ and D) three years later showing resolution of the dural thickening (C, arrowheads) and improved caliber of the superior sagittal sinus (D, arrow)
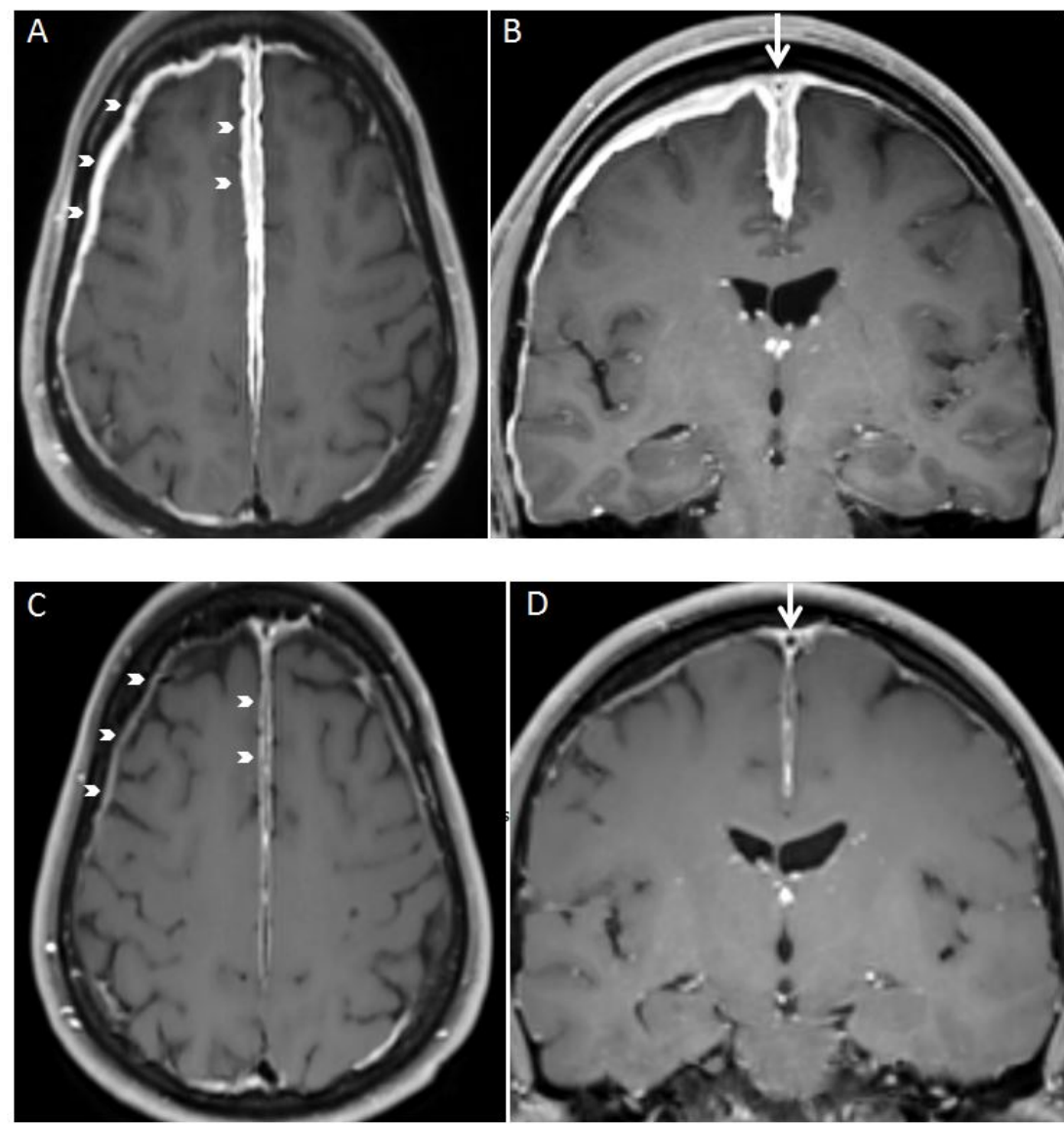
Figure2. Excisional biopsy of the right jugular lymph node: A: H\&E section showed regressed lymphoid follicles and markedly increased plasma cells (H\&E, x10). B-Plasma cells in the lymph node sinuses were highlighted by $\mathrm{CD} 138$ (IHC, x10). C: $\mathrm{IgG}$ was positive for majority of the plasma cells (IHC, x10). D: IgG4 was also positive for many plasma cells (IHC, x10).
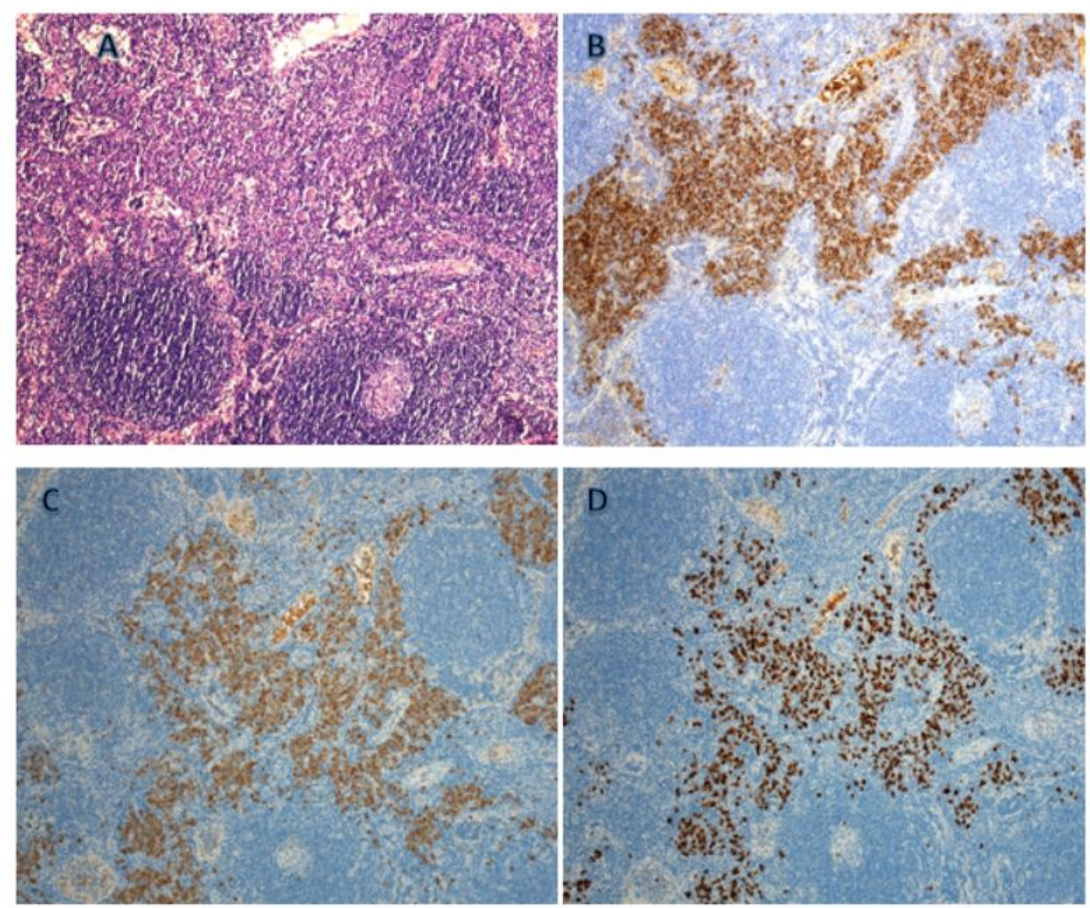

Figure3. IgG4 levels during treatment and follow up

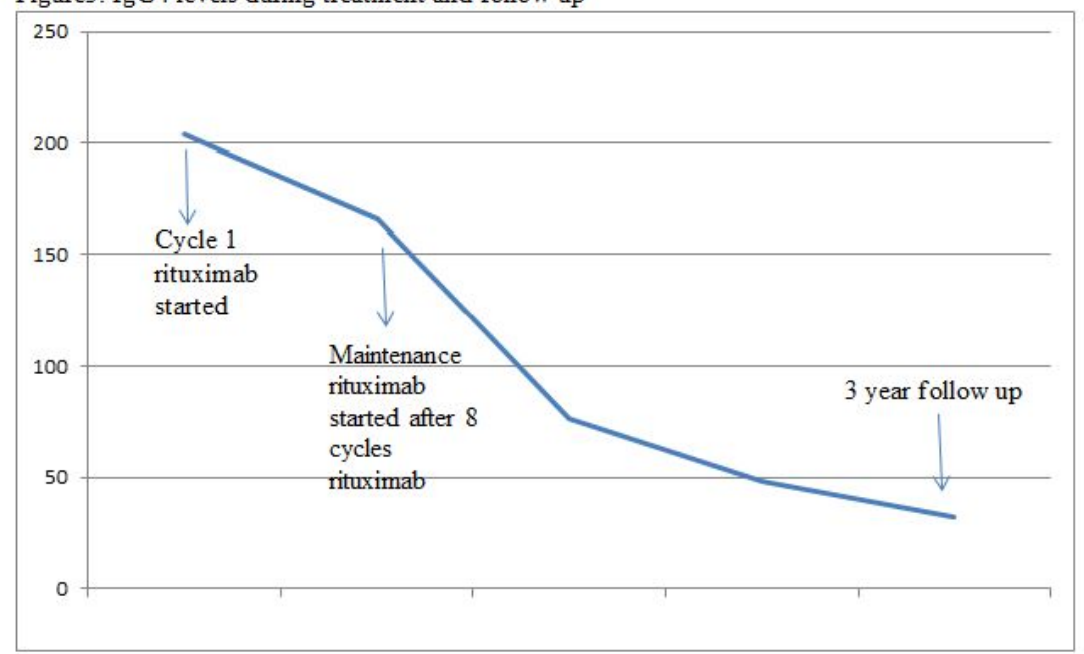

